\title{
A maternal high-protein diet predisposes female offspring to increased fat mass in adulthood whereas a prebiotic fibre diet decreases fat mass in rats
}

\author{
Megan C. Hallam ${ }^{1}$ and Raylene A. Reimer ${ }^{1,2 *}$ \\ ${ }^{1}$ Faculty of Kinesiology, University of Calgary, 2500 University Drive NW, Calgary, AB, Canada T2N $1 N 4$ \\ ${ }^{2}$ Department of Biochemistry and Molecular Biology, University of Calgary, 3330 Hospital Drive NW, Calgary, \\ $A B$, Canada T2N $4 N 1$ \\ (Submitted 18 October 2012 - Final revision received 8 February 2013 - Accepted 5 March 2013 - First published online 8 April 2013)
}

\begin{abstract}
The negative effects of malnourishment in utero have been widely explored; the effects of increased maternal macronutrient intake are not known in relation to high fibre, and have been inconclusive with regard to high protein. In the present study, virgin Wistar dams were fed either a control (C), high-protein ( $40 \%, \mathrm{w} / \mathrm{w}$; HP) or high-prebiotic fibre $(21.6 \%, \mathrm{w} / \mathrm{w}$; HF) diet throughout pregnancy and lactation. Pups consumed the $\mathrm{C}$ diet from 3 to 14.5 weeks of age, and then switched to a high-fat/sucrose diet for 8 weeks. A dual-energy X-ray absorptiometry scan and an oral glucose tolerance test were performed and plasma satiety hormones measured. The final body weight and the percentage of body fat were significantly affected by the interaction between maternal diet and offspring sex: weight and fat mass were higher in the female offspring of the HP $v$. HF dams. No differences in body weight or fat mass were seen in the male offspring. There was a significant sex effect for fasting and total AUC for ghrelin and fasting GIP, with females having higher levels than males. Liver TAG content and plasma NEFA were lower in the offspring of high-prebiotic fibre dams (HF1) than in those of high-protein dams (HP1) and control dams (C1). Intestinal expression of GLUT2 was decreased in HF1 and HP1 $v$. C1. The maternal HP and HF diets had lasting effects on body fat and hepatic TAG accumulation in the offspring, particularly in females. Whereas the HP diet predisposes to an obese phenotype, the maternal HF diet appears to reduce the susceptibility to obesity following a high-energy diet challenge in adulthood.
\end{abstract}

Key words: Maternal diet: Prebiotic fibre: Gut hormones: Fetal programming

The WHO projected that as of 2005, there were twenty million overweight children and 400 million obese adults worldwide, a number that is predicted to reach 700 million by $2015^{(1)}$. The rapid rise in obesity rates has been theorised to be at least partially linked to developmental programming or the ability of an insult occurring at a critical period in development to result in persistent effects on metabolism and health ${ }^{(2)}$. Compromised nutritional exposure of the fetus in utero has been implicated in programming of later CVD, hypertension and diabetes in offspring $^{(2)}$. Detrimental metabolic programming has been shown to affect the birth size and body weight of future generations, even up to twelve generations in rodents ${ }^{(3)}$.

Glucose and lipid metabolism are responsible for energy use and storage by the body and its various systems. Many of the genes that regulate glucose and lipid metabolism are nutrientresponsive and can therefore be up- or down-regulated in response to changes in diet composition ${ }^{(4)}$. Both fibre and protein are important dietary components that yield nutrient-gene interactions in the body ${ }^{(5)}$. The effects of consuming excess amounts of these macronutrients in the context of pregnancy and developmental programming are incompletely understood.

Depending on the type of dietary fibre examined, diets high in fibre can enhance satiety and reduce food intake, reduce hypercholesterolaemia, improve type 2 diabetes management $^{(6,7)}$ and even prevent pre-eclampsia ${ }^{(8)}$. The societal trend towards the consumption of highly processed and energydense foods has resulted in a decreased intake of dietary fibre $^{(9)}$. We have shown that a high-prebiotic fibre diet (approximately 5\%) is tolerated and effective in reducing body weight, fat mass and food intake in human subjects ${ }^{(10)}$. These same effects can be seen in rodents fed diets containing 10-20\% prebiotic fibre ${ }^{(11-13)}$. Despite the known benefits of fibre, pregnant women are not meeting current recommendations for dietary fibre intake ${ }^{(14,15)}$.

There are also large variations in protein intake in pregnant women, with some reports of intake as high as $350 \mathrm{~g} / \mathrm{d}$ of

Abbreviations: AIN, American Institute of Nutrition; C1, offspring of control dams; C, control; GIP, glucose-dependent insulinotropic polypeptide; GLP-1, glucagon-like peptide-1; HF1, offspring of high-prebiotic fibre dams; HF, high prebiotic fibre; HFS, high fat/high sucrose; HP1, offspring of high-protein dams; HP, high protein; HOMA-IR, homeostasis model assessment of insulin resistance; OGTT, oral glucose tolerance test; PYY, peptide tyrosine tyrosine; SGLT1, sodium glucose co-transporter 1. 
protein in the third trimester ${ }^{(16)}$. A high protein intake during pregnancy has been linked to low birth weight ${ }^{(17)}$, increased blood pressure ${ }^{(18,19)}$ and increased cortisol levels ${ }^{(20)}$. It has been previously shown in animal studies that a maternal diet high in protein can lead to fetal growth retardation and subsequently trigger increased fat mass in adulthood ${ }^{(21)}$.

We have previously shown that a high-protein diet introduced at weaning predisposes rats to an obese phenotype when they are given a high-energy diet in adulthood; whereas consumption of a high-prebiotic fibre diet during growth may provide some protection ${ }^{(22)}$. Furthermore, when dams were fed the same high-protein and high-fibre diets during pregnancy and lactation, plasma glucose at $28 \mathrm{~d}$ of age was lower in high-fibre $v$. control and high-protein offspring, and glucagon-like peptide-1 (GLP-1), a potent insulin secretagogue and anorexigenic hormone, was increased in high-fibre offspring ${ }^{(11)}$. In brown adipose tissue, high-protein offspring had increased resistin and $I L-6$ mRNA expression, two factors associated with inflammation and insulin resistance. Because changes in offspring were measured only from postnatal day 7 to 35 , we do not know whether these early changes persist into adulthood and to what extent they affect glucose control and adiposity into adulthood.

The objective of the present study was therefore to determine the long-term effects of maternal diets high in protein or prebiotic fibre content on the offspring's glucose control and adiposity in adulthood. Specifically, we examined body weight, fat mass and the expression of satiety hormones and genes related to glucose control and lipid storage in the offspring from dams consuming a control, high-fibre or high-protein diet during pregnancy and lactation. Given evidence that the developmental programming effects of early nutrition can be latent, we used an 8-week high-fat, high-sucrose (HFS) diet challenge in adulthood to unmask the potential effects of early programming.

\section{Methods}

\section{Ethical approval}

The University of Calgary Animal Care Committee approved the experimental protocol that was conducted in accordance with the Guide for the Care and Use of Laboratory Animals.

\section{Animals and diets}

A total of thirty-seven virgin Wistar dams were obtained from Charles River and housed in a temperature- and humidity-controlled facility with a $12 \mathrm{~h}$ light $-12 \mathrm{~h}$ dark cycle. After 1 week of acclimatisation, the animals were given one of three nutritionally complete experimental diets: high prebiotic fibre (HF, $21.6 \%(\mathrm{w} / \mathrm{w}), 1: 1$ ratio of oligofructose and inulin; $13.73 \mathrm{~kJ} / \mathrm{g}$ ); high protein $(\mathrm{HP}, 40 \%(\mathrm{w} / \mathrm{w}) ; 15.74 \mathrm{~kJ} / \mathrm{g})$; control (C, based on the American Institute of Nutrition (AIN)-93G; $15 \cdot 74 \mathrm{~kJ} / \mathrm{g}$ ). All maternal diets were mixed in house using ingredients purchased from Dyets, Inc.; the detailed composition has been published previously ${ }^{(4)}$. Dams consumed the diets for 1 week before being bred with male Wistar rats in wire-bottomed cages. Following the identification of a copulation plug, dams were housed individually and continued to consume their assigned experimental diet (C, HF or HP) until the pups were weaned. Dams were weighed weekly, and food intake was measured throughout week 2 of pregnancy.

\section{Body composition}

Pups were weighed on the day after birth, and litters then culled to ten pups with equal numbers of males and females where possible. Offspring were weighed weekly for the remainder of the study. Food intake was also measured for five consecutive days out of every $20 \mathrm{~d}$ by subtracting the weight of the cup and diet from the previous day's weight. At weaning (3 weeks), one male and one female pup were randomly selected from each litter to continue in the study until 22 weeks of age. By selecting one male and one female from each litter, we examined ten individual rats per sex that were not all from one litter, minimising the effect of any single dam. Pups were weaned onto the AIN$93 \mathrm{G}$ control diet ${ }^{(23)}$. Offspring were then switched to AIN-93M $(15.07 \mathrm{~kJ} / \mathrm{g})$ for maintenance at 10 weeks of age. At 14.5 weeks of age, offspring were fed a HFS diet $(19 \cdot 26 \mathrm{~kJ} / \mathrm{g})^{(12)}$ for 8 weeks. The HFS diet was composed of $(\mathrm{g} / 100 \mathrm{~g})$ : maize starch (5); casein (14), sucrose (51), soyabean oil (10), lard (10), Alphacel (5), AIN-93M mineral mix (3·5), AIN-93 vitamin mix (1), L-cystine (0.3) and choline bitartrate (0.25). Only one male and one female pup not selected for the study underwent a dual-energy X-ray absorptiometry scan (Hologic QDR-4500; Hologic, Inc.) while lightly anaesthetised using isoflurane 1 week post-weaning. Hologic QDR software for small animals was used to determine lean and fat mass. A separate group of pups referred to as reference rats ( $n 10$ male and $n 10$ female offspring from $n 5$ control diet dams) was weaned at 3 weeks of age onto the control diet (AIN-93G) and continued to consume this diet (AIN-93M after 10 weeks of age) throughout the study (i.e. no maternal intervention and no exposure to the HFS diet). This reference group, matched for age and sex with the intervention groups, provides a standard of normal growth in these rats.

\section{Oral glucose tolerance test and tissue sampling}

At the end of the 8 weeks of HFS diet consumption, rats were fasted overnight and an oral glucose tolerance test (OGTT) performed. Blood was sampled from the tip of the tail in conscious rats followed by an oral glucose administration $(2 \mathrm{~g} / \mathrm{kg})$. At 15 , 30, 60, 90 and $120 \mathrm{~min}$ post-oral glucose administration, additional blood was sampled from the tail and immediately analysed using a blood glucose meter (Accu-Chek Blood Glucose Meter; Roche). At $1 \mathrm{~d}$ before study termination, rats underwent a dual-energy X-ray absorptiometry scan under light anaesthetic as described previously. A second OGTT for satiety hormone analysis was performed at the time of terminal tissue collection. After an overnight fast, rats were anaesthetised with isoflurane and a fasting cardiac blood sample was taken. Rats were then given $50 \%$ dextrose $(\mathrm{w} / \mathrm{v})$ by oral administration at a dose of $2 \mathrm{~g} / \mathrm{kg}$. At 15, 30, 60 and $90 \mathrm{~min}$ post-oral dextrose administration, another cardiac blood sample was taken according to our previous study while rats were anaesthetised ${ }^{(24)}$. 
Blood was collected in tubes containing diprotin-A $(0 \cdot 034 \mathrm{mg} / \mathrm{ml}$ blood; MP Biomedicals); Sigma protease inhibitor $(1 \mathrm{mg} / \mathrm{ml}$ blood; Sigma-Aldrich) and Roche Pefabloc $(1 \mathrm{mg} / \mathrm{ml}$ blood; Roche), and then centrifuged at $1600 \mathrm{~g}$ for $12 \mathrm{~min}$ at $4^{\circ} \mathrm{C}$. Plasma was stored at $-80^{\circ} \mathrm{C}$ until analysis. The OGTT was a terminal procedure and after the $90 \mathrm{~min}$ blood collection, rats were killed via over-anaesthetisation and aortic cut. The liver, stomach, small intestine, caecum and colon were weighed, and then a sample was snap-frozen in liquid $\mathrm{N}_{2}$ and stored at $-80^{\circ} \mathrm{C}$.

\section{Plasma analysis}

A Milliplex Rat Gut Hormone kit (Millipore) and a Luminex instrument were used to measure ghrelin (active), insulin, amylin (active), leptin, glucose-dependent insulinotropic polypeptide (GIP, total) and peptide tyrosine tyrosine (PYY, total). An ELISA was used to measure active GLP-1 (Millipore). NEFA at fasting were measured using an enzymatic colorimetric assay according to the manufacturer's instructions (Wako Diagnostics). Homeostasis model assessment of insulin resistance (HOMA-IR) was calculated from fasting insulin and fasting glucose.

\section{Hepatic TAG analysis}

TAG content of the liver was quantified using $25 \mathrm{mg}$ tissue according to the manufacturer's guidelines of the glycerol phosphate oxidase (GPO) reagent set (Pointe Scientific, Inc.).

\section{RNA extraction and real-time $P C R$}

Total RNA was extracted from the stomach, small intestine, colon and liver using TRIzol reagent (Invitrogen). RT was performed with an input of $1 \mu \mathrm{g}$ of total RNA using the first-strand complementary DNA synthesis kit for RT-PCR (Invitrogen) with oligo $\mathrm{d}(\mathrm{T}) 15$ as a primer. Complementary DNA was amplified using primers synthesised by the University of Calgary Core DNA Services (Calgary) and analysed by realtime PCR. Primer sequences were according to our previous study ${ }^{(4)}$. A melt curve showed the melting point of the PCR product of interest. Glyceraldehyde-3-phosphate dehydrogenase $(G A P D H)$ was verified as a suitable housekeeping gene for the tissues of interest and GAPDH primers included as an internal control in the reactions. The $2^{-\Delta C_{\mathrm{T}}}$ method $\left(\Delta C_{\mathrm{T}}=C_{\mathrm{T}}\right.$ (gene of interest) $-C_{\mathrm{T}}$ (reference gene)) was utilised for the data analysis, where the threshold cycle $\left(C_{\mathrm{T}}\right)$ indicates the fractional cycle number at which the amount of the amplified target reaches a fixed threshold ${ }^{(25)} . \Delta C_{\mathrm{T}}$ is the difference in threshold cycles for the gene of interest and GAPDH.

\section{Statistical analysis}

All data are presented as means with their standard errors. Data collected from the dams were analysed with one-way ANOVA with Tukey's post hoc analysis. In offspring, a two-way ANOVA was used to compare the main effects of diet and sex, and their interaction. Only when a significant interaction effect was identified were all the six groups compared using a one-way ANOVA with Tukey's post hoc analysis. The reference group data are provided as a comparator for rats that did not undergo any intervention (either maternal diet manipulation or offspring's HFS diet consumption). Given that there was no intervention and they were for reference purposes alone, the reference group was not included in the statistical analysis. Given the numerous variables examined in the offspring, a Bonferroni correction was applied such that only $P \leq 0 \cdot 01$ was considered as significant. Statistical analysis was performed using PASW version 17.0 software (SPSS Inc.).

\section{Results}

\section{Dams and litters}

Of the thirty-seven dams originally obtained for the present study, twenty-four delivered viable litters. Of the control dams, three had spontaneous abortions and one exhibited abnormal behaviour towards her litter. The abnormal behaviour consisted of splitting the nest of pups into two at opposite ends of the cage and tending to one nest more than the other, thus resulting in greater weight gain in pups of one nest over the other. Of the HP dams, two had a number of pups that died within a week of delivery, resulting in litters too small to be used in the present study. In addition one HP dam delivered all stillborn pups and another also exhibited abnormal behaviour towards her litter. Of the HF dams, one did not conceive, one died during the first week of pregnancy from cardiac arrest, one became moribund after delivery of her pups and another two died at 1 and 2 weeks, respectively, after delivery due to intestinal complications.

The total weight gain during pregnancy was greater in the $\mathrm{C}$ and HP dams compared with the HF dams $(P<0.05$; Table 1). The birth weight of female offspring from the HF dams was lower than that from the HP and C dams (Table 1), whereas male offspring birth weights did not differ (hereafter, offspring are referred to as HF1, HP1 or C1). There were no differences in the number of pups delivered and the number of males and females, or stillborns across the diet groups.

\section{Offspring growth and food intake}

As measured by dual-energy X-ray absorptiometry at 4 weeks of age, the diet but not sex affected the percentage of body fat, with HF1 having lower levels than C1 (C1: 20.0 (sE 0.9)\%, HP1: 18.4 (sE 1.7)\%, HF1: $15 \cdot 4$ (sE 1.0)\%; $P=0.01$ ). As expected with growth, there was a significant effect of week $(P=0.0001)$ and a week $\times$ sex interaction $(P=0.001)$ for body weight from 4 to 22 weeks of age, with males having a higher body weight than females (Fig. 1). The final body weight was affected by the interaction of diet and sex ( $P=0 \cdot 01$ ), with female HP1 having a higher body weight than C1 and HF1 (Fig. 2(A)). Similarly, for the percentage of body fat, the interaction between diet and sex affected the body fat $(P=0 \cdot 01)$, with female HP1 having a higher body fat than $\mathrm{C} 1$ which in turn were found to have a higher body fat than HF1 (Fig. 2(B)). When maternal weight gain was 
Table 1. Weight gain and litter statistics of dams fed a control, high-protein or high-prebiotic fibre diet during pregnancy and lactation*

(Mean values with their standard errors, $n 8-10$ per group)

\begin{tabular}{|c|c|c|c|c|c|c|}
\hline & \multicolumn{2}{|c|}{ Control } & \multicolumn{2}{|c|}{ High protein } & \multicolumn{2}{|c|}{ High fibre } \\
\hline & Mean & SE & Mean & SE & Mean & SE \\
\hline Dam weight gain during pregnancy $(\mathrm{g})$ & $148 \cdot 9^{a}$ & 8.9 & $146 \cdot 5^{\mathrm{a}}$ & $7 \cdot 3$ & $113 \cdot 8^{\mathrm{b}}$ & 8.4 \\
\hline Dam energy intake $(\mathrm{kJ} / \mathrm{d})$ & $432 \cdot 2^{\mathrm{a}}$ & $23 \cdot 8$ & $468 \cdot 2^{a}$ & $20 \cdot 9$ & $344 \cdot 3^{b}$ & $20 \cdot 9$ \\
\hline Dam food intake $(\mathrm{g} / \mathrm{d})$ & $27 \cdot 5^{\mathrm{a}, \mathrm{b}}$ & 1.5 & $29 \cdot 7^{\mathrm{a}}$ & 1.5 & $24 \cdot 6^{\mathrm{b}}$ & 1.0 \\
\hline Female pup birth weight (g) & $5 \cdot 9^{\mathrm{a}}$ & 0.8 & $6 \cdot 1^{\mathrm{a}}$ & 0.7 & $5 \cdot 3^{\mathrm{b}}$ & 0.7 \\
\hline Male pup birth weight $(\mathrm{g})$ & $6 \cdot 0$ & 0.9 & $6 \cdot 1$ & 0.8 & $6 \cdot 0$ & 0.8 \\
\hline Pups $(n)$ & $14 \cdot 8$ & 1.0 & $15 \cdot 1$ & 0.8 & $14 \cdot 8$ & 1.0 \\
\hline Males $(n)$ & $7 \cdot 8$ & 0.8 & 8.4 & 0.7 & $7 \cdot 0$ & 0.8 \\
\hline Females $(n)$ & $7 \cdot 0$ & 0.8 & 6.5 & 0.6 & $7 \cdot 8$ & 0.7 \\
\hline
\end{tabular}

${ }^{a, b}$ Mean values with unlike superscript letters were significantly different between the diets $(P<0.05)$.

${ }^{*}$ Food and energy intake was measured during the second week of pregnancy.

examined as a covariate, no significant effect was found for the female offspring's final body weight $(P=0 \cdot 112)$ or percentage of body fat $(P=0.069)$. There were no differences in the naso-anal length within male or female offspring, and there were no differences between the diet groups for any organ weights or lengths (data not shown). Independently, time and sex affected the offspring's intake of the control diet from 4 to 13 weeks of age wherein food intake increased with increasing age and males consumed more food than females $(P<0 \cdot 01)$. There were no differences between the diet groups during this period. When rats were switched to the HFS diet, there was a significant effect of sex $(P=0 \cdot 001)$, with male rats consuming more of the diet than females (Fig. 2(C)).

\section{Plasma satiety hormones and blood glucose}

Fasting values and AUC were examined for seven appetiteregulating hormones. At fasting, there was a significant effect of sex on insulin $(P=0 \cdot 001)$, with males having higher levels than females (Table 2). In contrast, females had higher fasting levels of ghrelin $(P=0.001)$ and GIP $(P=0.002)$ than males. Only fasting GIP was significantly affected by diet $(P=0 \cdot 004)$, with HF1 having higher levels than C1 and HP1. For the AUC, which represents the exposure to the hormone of interest over the entire course of the OGTT, females had higher ghrelin than males $(P=0.001$; Table 3$)$. The diet affected the GIP AUC ( $P=0.0013)$ with HF1 having higher levels than HP1 but not C1. Similarly, the PYY AUC was higher in HF1 $(P=0.0015)$ compared with HP1 but not C1. There were no differences between sexes for GIP or PYY AUC. There were no differences in fasting or AUC for glucose (Tables 2 and 3). Independently, diet $(P=0.004)$ and sex $(P=0.001)$ but not their interaction affected HOMA-IR, with males having higher values than females and C1 having higher levels than HP1 at the end of the study (Table 2).

\section{NEFA and liver TAG}

Independently, maternal diet $(P=0.001)$ and sex $(P=0 \cdot 001)$ affected the liver TAG content. Hepatic TAG concentration was lower in females than in males and lower in HF1 than in $\mathrm{C} 1$ or HP1 (Fig. 3(A)). Independently, maternal diet $(P=0 \cdot 001)$ and sex $(P=0 \cdot 001)$ also affected plasma NEFA concentrations, with males having higher levels than females and HP1 having higher levels than C1 and HF1 (Fig. 3(B)).

\section{Gastrointestinal tract gene expression}

In the stomach, maternal diet affected ghrelin gene expression $(P=0 \cdot 01)$, with HP1 having higher levels than HF1 (Table 4). The interaction of maternal diet and sex affected the mRNA levels of sodium glucose co-transporter 1 ( $S G L T 1 ; P=0 \cdot 014)$ in the ileum, with male HF1 having lower levels than male HP1 and female C1. Maternal diet alone affected the expression of GLUT2 ( $P=0 \cdot 002)$, with HP1 and HF1 having lower levels than $\mathrm{C} 1$.

\section{Hepatic gene expression}

Maternal diet affected the gene expression of hepatic fatty acid synthase (FAS) ( $P=0.006)$, with HP1 having lower levels than HF1 and C1 (Table 5). Phosphoenolpyruvate carboxykinase (PEPCK; $\quad P=0.006$ ) differed between sexes, with males having higher mRNA levels than females. The interaction

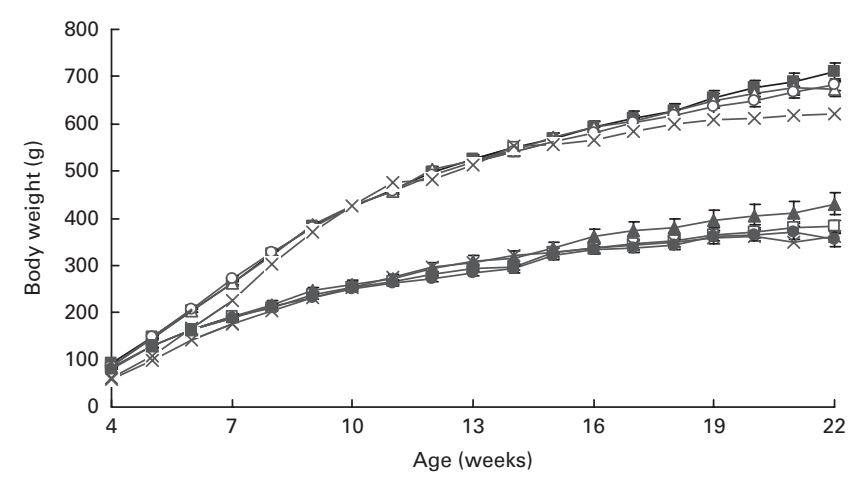

Fig. 1. Longitudinal body weight in the female and male offspring of dams fed a control, high-protein or high-prebiotic fibre diet during pregnancy and lactation. Values are means ( $n 10$ males and $n 10$ females), with their standard errors represented by vertical bars. There were significant effects for week $(P=0.0001)$ and the week $\times$ sex interaction $(P=0.001)$. Male: - , control; $\triangle-$, protein; $-\circ-$, fibre; $-\times-$, reference. Female: $\_-$, control; -protein; - , fibre; $\_$, reference. 

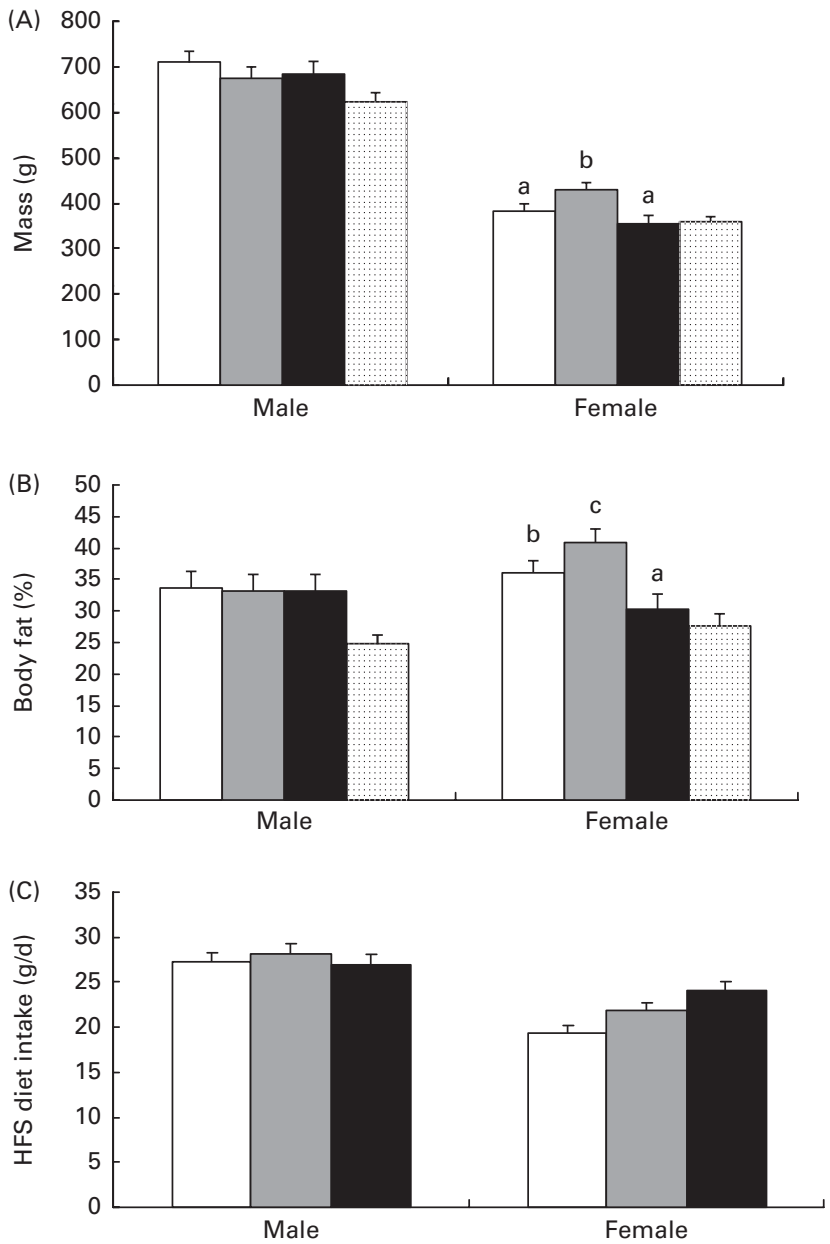

Fig. 2. Final body weight, percentage of fat and high fat, sucrose diet intake in the offspring of dams fed a control $(\square)$, high-protein ( $\square$ ) or high-prebiotic fibre ( $\square$ ) diet. (A) Body weight was greater in the female offspring of high-protein dams (HP1) than in those of high-prebiotic fibre dams (HF1) and control dams (C1) $(P=0.043)$, (B) percentage of fat was greater in HP1 females than in HF1 and $\mathrm{C} 1$ and (C) high-fat/sucrose (HFS) diet consumption was not different between the diet groups for males or females. Values are means ( $n 10$ males and $n 10$ females), with their standard errors represented by vertical bars. ${ }^{\mathrm{a}, \mathrm{b}, \mathrm{c}}$ Mean values with unlike letters were significantly different between the diets $(P \leq 0 \cdot 01)$. (A, B) There was a significant diet $\times$ sex interaction effect $(P=0.01)$ and $(C)$ a significant effect for sex $(P=0.001)$. D, Reference.

between maternal diet and sex affected PPAR $\gamma$ CO-activator 1- $\alpha(P G C 1 \alpha, P=0.006)$. PGC1 $\alpha$ mRNA levels were lower in all males and HF1 females compared with female C1. There were no differences in sterol regulatory element-binding protein 1c (SREBP1C) or acetyl-CoA carboxylase 1 (ACC1) expression (data not shown).

\section{Discussion}

Maternal diet is a well-recognised environmental factor that influences the health of offspring later in life and is in part attributed to epigenetic changes ${ }^{(26)}$. In the present study, examining the influence of maternal diets high in protein or prebiotic fibre, we showed a difference in susceptibility to an obese phenotype in the offspring of dams fed these diets and a distinct sex effect, females being affected while males were not. The pattern of growth and development in these offspring may shed some light on the lasting influence of maternal diet. Accelerated postnatal growth or 'catch-up' growth has been associated with later metabolic disease and susceptibility to obesity ${ }^{(27)}$. We observed catch-up growth in HF1 offspring during the first 2 weeks of life. This rapid growth was evident in female HF offspring, wherein their birth weight was significantly lower than HP1 and C1 female pups but no longer different from the other groups at weaning. This observation is interesting on several fronts given that there were no lasting detrimental effects on adiposity and the availability of food to the dams did not change, although the offspring may have altered their suckling habits or maternal diet may have affected milk composition. While it has recently been shown that milk from the HP dams compromises offspring growth due to impaired lactational function $^{(28)}$, it is not known how the HF diet affects milk composition. Maternal weight loss during lactation does not appear to explain the differences in the rate of growth in pups, given that there were no differences among the control, HP and HF dams. However, maternal weight gain during pregnancy was affected by the diet, and the HF dams gained less weight compared with the HP and C dams. It may be tempting to speculate that weight gain, independently of dietary exposure, could have influenced offspring growth; however, we have recently demonstrated that this may not be the case. Consistent with the magnitude of differences in maternal weight gain during pregnancy achieved in the present study, we recently showed that offspring body weight was not altered when maternal weight gain differed by $30-35 \mathrm{~g}$ on AIN-93G-based diets (AJ Eslinger and RA Reimer, unpublished results). This is in contrast to a maternal HFS diet that not only resulted in a higher pregnancy weight gain, but probably interacted with the fat and sugar content of the diet to produce increased offspring body weight as well (AJ Eslinger and RA Reimer, unpublished results). Outside of maternal influences, it is possible that catch-up growth in HF1 female offspring was influenced by changes to gut microbial communities. Given the known bifidogenic effect of prebiotics, the HF1 offspring may have acquired a unique profile of bacterial species, or simply a greater number of bacteria that could have led to an initial increase in energy harvest similar to that which has been seen with germ-free mice colonised with microbiota ${ }^{(29)}$.

It is not clear what factors are responsible for catch-up growth seen in the HF1 animals; however, it is clear that they avoided the predicted increase in body weight and adiposity typically seen with accelerated postnatal growth ${ }^{(30)}$. In fact, at 4 weeks of age, the percentage of body fat was lower in HF1 males and females than in C1. By the end of the study, male body weight and fat mass did not differ from the other two groups, but HF1 females retained a lower body weight and percentage of body fat than HP1 offspring. Fat mass in HF1 females was not only lower than that in HP1 but also decreased in comparison with $\mathrm{C} 1$. The elevated percentage of body fat in HP1 is consistent with other studies showing increased fat mass in the offspring of dams fed a high-protein diet during lactation ${ }^{(31)}$. Part of the 
Table 2. Fasting blood glucose and plasma satiety hormones in the offspring

(Mean values with their standard errors, $n 8-10$ per group)

\begin{tabular}{|c|c|c|c|c|c|c|c|c|c|c|c|c|}
\hline & \multirow[b]{2}{*}{ Sex } & \multicolumn{2}{|c|}{ Control } & \multicolumn{2}{|c|}{ Protein } & \multicolumn{2}{|c|}{ Fibre } & \multicolumn{2}{|c|}{ Reference } & \multirow[b]{2}{*}{ Diet } & \multirow[b]{2}{*}{ Sex } & \multirow[b]{2}{*}{ Diet $\times$ sex } \\
\hline & & Mean & SE & Mean & SE & Mean & SE & Mean & SE & & & \\
\hline \multirow[t]{2}{*}{ Glucose* $(\mathrm{mmol} / \mathrm{l})$} & M & $5 \cdot 2$ & 0.2 & 5.4 & 0.2 & 5.9 & 0.4 & 4.6 & 0.2 & 0.216 & 0.134 & 0.547 \\
\hline & $\mathrm{F}$ & $6 \cdot 0$ & 0.4 & 5.5 & 0.3 & $6 \cdot 2$ & 0.5 & 5.4 & 0.5 & & & \\
\hline \multirow[t]{2}{*}{ Insulin (pg/ml) } & M & 3578 & 501 & 2703 & 790 & 3395 & 794 & 2385 & 425 & 0.428 & 0.001 & 0.576 \\
\hline & $\mathrm{F}$ & 2154 & 334 & 1680 & 326 & 1186 & 137 & 1147 & 175 & & & \\
\hline \multirow[t]{2}{*}{ Amylin (pg/ml) } & $\mathrm{M}$ & $50 \cdot 4$ & 3.6 & $46 \cdot 0$ & $4 \cdot 6$ & 58.5 & $7 \cdot 4$ & 77.9 & $7 \cdot 8$ & 0.476 & 0.079 & 0.049 \\
\hline & $\mathrm{F}$ & $65 \cdot 6$ & $4 \cdot 6$ & $59 \cdot 0$ & $4 \cdot 1$ & 51.0 & 3.9 & $80 \cdot 0$ & $8 \cdot 4$ & & & \\
\hline \multirow[t]{2}{*}{ Ghrelin (ng/ml) } & $\mathrm{M}$ & $187 \cdot 2$ & $25 \cdot 8$ & $185 \cdot 6$ & $18 \cdot 4$ & $267 \cdot 2$ & 33.0 & 133.4 & 24.5 & 0.046 & 0.001 & 0.735 \\
\hline & $\mathrm{F}$ & $410 \cdot 3$ & $28 \cdot 0$ & 376.9 & 17.9 & $446 \cdot 0$ & 47.5 & $348 \cdot 3$ & $77 \cdot 9$ & & & \\
\hline \multirow{2}{*}{ GIP (ng/ml) } & M & $37 \cdot 8^{\mathrm{a}}$ & 4.7 & $32 \cdot 4^{\mathrm{a}}$ & 3.0 & $58 \cdot 6^{\mathrm{b}}$ & 6.9 & 51.0 & 4.2 & 0.004 & 0.002 & 0.255 \\
\hline & $\mathrm{F}$ & $54 \cdot 1^{a}$ & $5 \cdot 4$ & $52 \cdot 8^{a}$ & $5 \cdot 0$ & $61 \cdot 8^{b}$ & $4 \cdot 7$ & $57 \cdot 8$ & $8 \cdot 3$ & & & \\
\hline \multirow[t]{2}{*}{ PYY (pg/ml) } & M & $68 \cdot 7$ & 4.9 & $62 \cdot 1$ & 3.7 & $70 \cdot 7$ & $6 \cdot 9$ & 39.9 & $2 \cdot 8$ & 0.335 & 0.869 & 0.859 \\
\hline & $\mathrm{F}$ & $68 \cdot 1$ & $3 \cdot 3$ & 64.0 & 4.4 & $67 \cdot 6$ & $3 \cdot 4$ & 57.8 & $5 \cdot 1$ & & & \\
\hline \multirow[t]{2}{*}{ GLP-1 (pg/ml) } & M & $7 \cdot 2$ & 0.6 & $5 \cdot 6$ & 0.7 & $5 \cdot 8$ & 0.5 & 41.4 & 3.7 & 0.742 & 0.392 & 0.237 \\
\hline & $\mathrm{F}$ & 5.7 & 0.5 & $6 \cdot 2$ & 0.5 & $5 \cdot 8$ & 0.4 & $48 \cdot 2$ & $5 \cdot 2$ & & & \\
\hline \multirow[t]{2}{*}{ Leptin (ng/ml) } & $\mathrm{M}$ & $23 \cdot 4$ & 5.94 & $17 \cdot 8$ & 3.19 & $22 \cdot 29$ & 3.37 & $5 \cdot 21$ & 0.54 & 0.897 & 0.023 & 0.301 \\
\hline & $\mathrm{F}$ & 13.9 & $1 \cdot 14$ & $17 \cdot 32$ & 2.48 & $11 \cdot 82$ & 2.85 & 4.51 & 0.89 & & & \\
\hline \multirow[t]{2}{*}{ HOMA-IR } & M & $18 \cdot 8^{\mathrm{b}}$ & $1 \cdot 8$ & $9 \cdot 5^{\mathrm{a}}$ & $2 \cdot 0$ & $13 \cdot 7^{a, b}$ & $2 \cdot 3$ & $11 \cdot 8$ & $2 \cdot 1$ & 0.004 & 0.001 & 0.460 \\
\hline & $\mathrm{F}$ & $11 \cdot 0^{b}$ & $2 \cdot 0$ & $6 \cdot 4^{\mathrm{a}}$ & $2 \cdot 2$ & $6 \cdot 3^{a, b}$ & $2 \cdot 3$ & 6.4 & 0.96 & & & \\
\hline
\end{tabular}

GIP, glucose-dependent insulinotropic polypeptide; PYY, peptide tyrosine tyrosine; GLP-1, glucagon-like peptide-1; HOMA-IR, homeostasis model assessment of insulin resistance.

${ }^{a, b}$ Mean values with unlike superscript letters were significantly different between the diets $(P \leq 0.01)$.

* Glucose concentrations were measured during an oral glucose tolerance test (OGTT) performed on conscious animals using a tail nick 1 week before study termination, while all other hormone data were from anaesthetised rats at the terminal OGTT.

reason behind this shift to fat mass may be impaired muscle growth, which has been shown in offspring suckled by HP dams ${ }^{(32)}$. Although we did not observe the growth retardation in HP1 offspring that has been demonstrated previously ${ }^{(33)}$, it is possible that growth restriction of lesser magnitude could have predisposed the HP1 animals to increased adipose accumulation as adults, especially when exposed to a HFS diet in adulthood. Postnatal increases in body growth seem to outpace increases in muscle growth in the offspring of dams fed a HP diet during lactation ${ }^{(32)}$, and this may have contributed to the higher percentage of body fat that we observed both at 4 weeks and 22 weeks of age.

Maternal satiety has been implicated as a key factor influencing catch-up weight gain, with levels of leptin and ghrelin in the cord blood able to predict catch-up growth in human subjects $^{(34,35)}$, which in turn relate to food intake later in life ${ }^{(36)}$. While plasma concentrations of these satiety hormones were not measured in our offspring at birth, we speculate that

Table 3. AUC for blood glucose and plasma satiety hormones in the offspring during the oral glucose tolerance tests

(Mean values with their standard errors, $n 8-10$ per group)

\begin{tabular}{|c|c|c|c|c|c|c|c|c|c|c|c|c|}
\hline & \multirow[b]{2}{*}{ Sex } & \multicolumn{2}{|c|}{ Control } & \multicolumn{2}{|c|}{ Protein } & \multicolumn{2}{|c|}{ Fibre } & \multicolumn{2}{|c|}{ Reference } & \multirow[b]{2}{*}{ Diet } & \multirow[b]{2}{*}{ Sex } & \multirow[b]{2}{*}{ Diet $\times$ sex } \\
\hline & & Mean & SE & Mean & SE & Mean & SE & Mean & SE & & & \\
\hline \multirow[t]{2}{*}{ Glucose* $(\mathrm{mmol} / /$ per $90 \mathrm{~min})$} & $\mathrm{M}$ & 998 & $27 \cdot 6$ & 931 & $30 \cdot 8$ & 977 & 41.5 & 955 & $90 \cdot 0$ & 0.12 & 0.49 & 0.47 \\
\hline & $\mathrm{F}$ & 1052 & 56.9 & 979 & 22.4 & 942 & $27 \cdot 4$ & 969 & $43 \cdot 7$ & & & \\
\hline \multirow[t]{2}{*}{ Insulin (ng/ml per $90 \mathrm{~min})$} & M & 457 & 36.4 & 390 & $48 \cdot 1$ & 387 & $32 \cdot 6$ & 275 & $30 \cdot 2$ & 0.46 & 0.027 & 0.49 \\
\hline & $\mathrm{F}$ & 330 & 41.8 & 366 & $58 \cdot 3$ & 296 & 38.6 & 202 & $18 \cdot 3$ & & & \\
\hline \multirow[t]{2}{*}{ Amylin (pg/ml per $90 \mathrm{~min})$} & $\mathrm{M}$ & 5062 & 426 & 3865 & 264 & 5207 & 631 & 5785 & 587 & 0.023 & 0.71 & 0.016 \\
\hline & $\mathrm{F}$ & 5519 & 424 & 4598 & 295 & 3643 & 347 & 5765 & 669 & & & \\
\hline \multirow[t]{2}{*}{ Ghrelin (ng/ml per $90 \mathrm{~min})$} & $\mathrm{M}$ & $13 \cdot 0$ & $2 \cdot 6$ & $12 \cdot 1$ & $1 \cdot 8$ & $17 \cdot 2$ & $2 \cdot 3$ & 14.6 & 1.9 & 0.41 & 0.001 & 0.59 \\
\hline & $\mathrm{F}$ & 24.9 & 2.8 & 22.5 & 3.1 & $24 \cdot 2$ & 1.2 & $31 \cdot 8$ & 4.4 & & & \\
\hline \multirow[t]{2}{*}{ GIP (pg/ml per $90 \mathrm{~min})$} & M & $6285^{\mathrm{a}, \mathrm{b}}$ & 589 & $3943^{\mathrm{a}}$ & 272 & $7819^{b}$ & 1871 & 5853 & 1071 & 0.013 & 0.55 & 0.90 \\
\hline & $\mathrm{F}$ & $6662^{a, b}$ & 599 & $5031^{a}$ & 1552 & $7928^{b}$ & 1699 & 4068 & 284 & & & \\
\hline \multirow[t]{2}{*}{ PYY (pg/ml per $90 \mathrm{~min})$} & M & $7793^{a, b}$ & 600 & $5962^{a}$ & 519 & $8123^{b}$ & 825 & 3840 & 153 & 0.015 & $0 \cdot 10$ & 0.29 \\
\hline & $\mathrm{F}$ & $7360^{a, b}$ & 560 & $5868^{a}$ & 339 & $7262^{b}$ & 502 & 5230 & 358 & & & \\
\hline \multirow[t]{2}{*}{ GLP-1 (pg/ml per $90 \mathrm{~min})$} & $\mathrm{M}$ & 621 & 39.8 & 542 & $50 \cdot 2$ & 546 & $58 \cdot 1$ & 414 & $36 \cdot 7$ & 0.43 & 0.11 & 0.53 \\
\hline & $\mathrm{F}$ & 517 & 42.5 & 535 & $25 \cdot 4$ & 479 & $30 \cdot 2$ & 482 & $52 \cdot 0$ & & & \\
\hline \multirow[t]{2}{*}{ Leptin (ng/ml per 90 min) } & $\mathrm{M}$ & 2398 & 590 & 1870 & 330 & 1807 & 209 & 563 & 78 & 0.35 & 0.039 & 0.24 \\
\hline & $\mathrm{F}$ & 1297 & 160 & 1919 & 318 & 1047 & 239 & 405 & 51 & & & \\
\hline
\end{tabular}

GIP, glucose-dependent insulinotropic polypeptide; PYY, peptide tyrosine tyrosine; GLP-1, glucagon-like peptide-1.

${ }^{a, b}$ Mean values with unlike superscript letters were significantly different between the diets $(P \leq 0.01)$.

* Glucose data were taken from an oral glucose tolerance test (OGTT) performed on conscious animals using a tail nick 1 week before study termination, while all other hormone data were from anaesthetised rats at the terminal OGTT. 

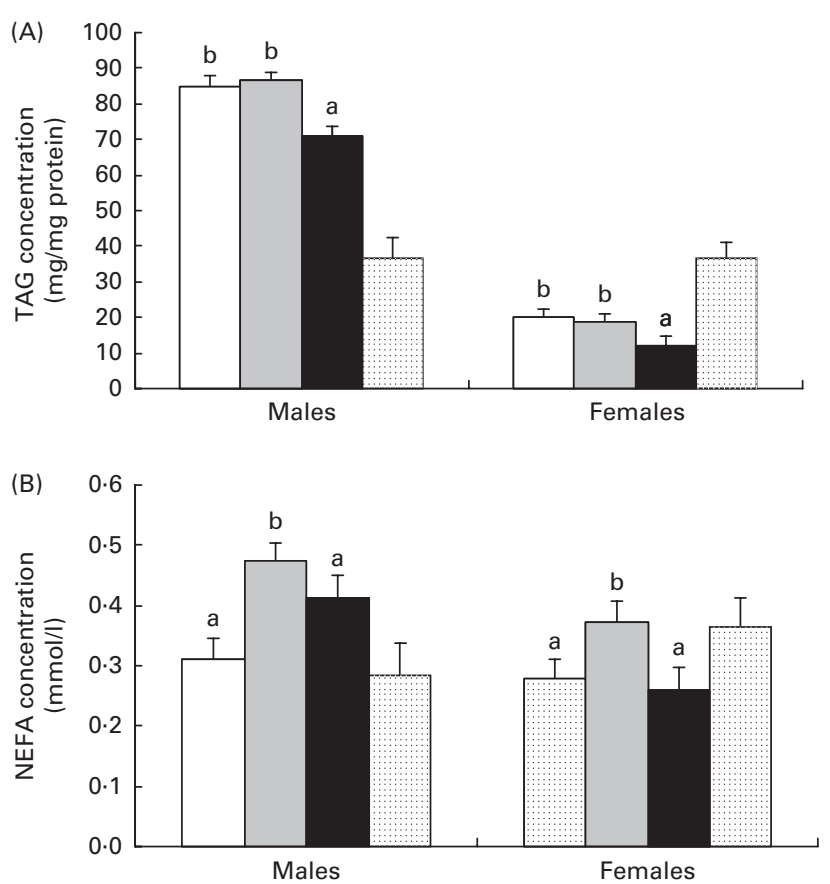

Fig. 3. (A) Hepatic TAG content and (B) plasma NEFA in the female and male offspring of dams fed a control $(\square)$, high-protein ( $\square$ ) or high-prebiotic fibre ( $\square$ ) diet during pregnancy and lactation. Values are means ( $n 10$ males and $n 10$ females), with their standard errors represented by vertical bars. ${ }^{a, b}$ Mean values with unlike letters were significantly different between the diets $(P \leq 0.01)$. (A, B) There were significant effects for diet $(P=0.001)$ and $\operatorname{sex}(P=0.001)$. $\square$, Reference.

they may have played a role, especially since HF1 female offspring consumed approximately $25 \%$ more HFS diet from 14 to 22 weeks of age than $\mathrm{C} 1$ females (although this did not reach statistical significance). In our previous study, we observed a decrease in plasma GLP-1 and amylin at $7 \mathrm{~d}$ of age in the offspring of dams fed a HF $v$. HP diet ${ }^{(11)}$. Both GLP-1 and amylin reduce food intake and their lower levels at birth could be associated with greater food consumption and accelerated growth. Despite a lower birth weight in females, early catch-up growth and a higher intake of the HFS diet in adulthood, HF1 offspring did not gain excessive body weight or fat, suggesting that other mechanisms were at work that had a greater influence than the catch-up growth itself. While glucose control was not negatively affected in HF1 compared with the controls, HOMA-IR scores were still higher than HP1. It is possible that the catch-up growth had a negative impact on insulin sensitivity that may not be fully apparent until an older age. Other negative effects of catch-up growth, such as decreased longevity and/or senescence in various tissues ${ }^{(36)}$, may also develop but were not measured in the present study, and may have been counteracted by exposure to prebiotic fibre, which has been shown to increase longevity ${ }^{(37)}$.

The offspring of HF dams had lower levels of liver TAG than HP1. While elevated plasma TAG has been shown in the offspring of dams fed a high-protein diet during lactation ${ }^{(31)}$, the TAG-lowering effect of the maternal HF diet in offspring is a novel finding. Oligofructose has been shown to decrease the production of TAG in the liver, as well as increase the catabolism of lipoproteins rich in $\mathrm{TAG}^{(38)}$. In the present study, the reduced hepatic TAG content is intriguing given that the rats were not directly exposed to oligofructose, nor were there diet differences in the expression of acetyl-CoA carboxylase, an enzyme in the fatty acid synthesis pathway. NEFA levels were also elevated in our HP1 animals, indicating the availability of lipid as a fuel. The elevated NEFA that we observed seem to be consistent with the shift, albeit transient, towards oxidative metabolism and away from glycolytic

Table 4. Intestinal gene expression in the offspring of dams fed a control, high-protein or high-prebiotic fibre diet during pregnancy and lactation

(Mean values with their standard errors, $n 8-10$ per group)

\begin{tabular}{|c|c|c|c|c|c|c|c|c|c|c|}
\hline & \multirow[b]{3}{*}{ Sex } & \multicolumn{6}{|c|}{ Maternal diet } & & & \\
\hline & & \multicolumn{2}{|c|}{ Control } & \multicolumn{2}{|c|}{ High protein } & \multicolumn{2}{|c|}{ High fibre } & \multicolumn{3}{|c|}{$P$ (two-way ANOVA) } \\
\hline & & Mean & SE & Mean & SE & Mean & SE & Diet & Sex & Diet $\times$ sex \\
\hline \multicolumn{11}{|l|}{ Stomach } \\
\hline Ghrelin & $\begin{array}{l}M \\
F\end{array}$ & $\begin{array}{l}71 \cdot 1^{\mathrm{a}, \mathrm{b}} \\
89 \cdot 3^{\mathrm{a}, \mathrm{b}}\end{array}$ & $\begin{array}{l}27 \cdot 0 \\
29 \cdot 0\end{array}$ & $\begin{array}{r}93 \cdot 3^{\mathrm{b}} \\
205 \cdot 5^{\mathrm{b}}\end{array}$ & $\begin{array}{l}32 \cdot 0 \\
61 \cdot 7\end{array}$ & $\begin{array}{l}46 \cdot 4^{\mathrm{a}} \\
30 \cdot 6^{\mathrm{a}}\end{array}$ & $\begin{array}{l}15.5 \\
11.8\end{array}$ & 0.010 & 0.12 & $0 \cdot 15$ \\
\hline \multicolumn{11}{|l|}{ Duodenum } \\
\hline GIP & $\begin{array}{l}M \\
F\end{array}$ & $\begin{array}{l}22 \cdot 1 \\
22 \cdot 3\end{array}$ & $\begin{array}{l}1.8 \\
2.3\end{array}$ & $\begin{array}{l}27 \cdot 3 \\
31 \cdot 4\end{array}$ & $\begin{array}{l}3.8 \\
4.4\end{array}$ & $\begin{array}{l}26 \cdot 0 \\
15 \cdot 8\end{array}$ & $\begin{array}{l}3.2 \\
2.4\end{array}$ & 0.029 & 0.458 & 0.089 \\
\hline \multicolumn{11}{|l|}{ Ileum } \\
\hline Proglucagon & $\begin{array}{l}M \\
F\end{array}$ & $\begin{array}{l}46 \cdot 2 \\
60 \cdot 9\end{array}$ & $\begin{array}{r}12 \cdot 1 \\
8.8\end{array}$ & $\begin{array}{r}64.5 \\
194.6\end{array}$ & $\begin{array}{l}13.9 \\
52.7\end{array}$ & $\begin{array}{c}96 \cdot 1 \\
104\end{array}$ & $\begin{array}{l}19 \cdot 3 \\
20 \cdot 3\end{array}$ & $0 \cdot 018$ & 0.019 & 0.035 \\
\hline SGLT1 & $\begin{array}{l}M \\
F\end{array}$ & $\begin{array}{l}43 \cdot 4^{x, y} \\
58 \cdot 0^{y}\end{array}$ & $\begin{array}{l}4.6 \\
7.6\end{array}$ & $\begin{array}{l}55 \cdot 6^{y} \\
33 \cdot 0^{x, y}\end{array}$ & $\begin{array}{r}11.5 \\
3.3\end{array}$ & $\begin{array}{l}26 \cdot 4^{x} \\
37 \cdot 7^{x, y}\end{array}$ & $\begin{array}{l}2 \cdot 9 \\
5 \cdot 3\end{array}$ & 0.012 & 0.84 & 0.014 \\
\hline GLUT2 & $\begin{array}{l}M \\
F\end{array}$ & $\begin{array}{l}22 \cdot 5^{\mathrm{b}} \\
19 \cdot 6^{\mathrm{b}}\end{array}$ & $\begin{array}{l}6.9 \\
5.2\end{array}$ & $\begin{array}{l}6 \cdot 9^{\mathrm{a}} \\
4 \cdot 9^{\mathrm{a}}\end{array}$ & $\begin{array}{l}1.7 \\
1.1\end{array}$ & $\begin{array}{r}14 \cdot 1^{\mathrm{a}} \\
4 \cdot 7^{\mathrm{a}}\end{array}$ & $\begin{array}{l}4.9 \\
1.3\end{array}$ & 0.002 & 0.18 & 0.65 \\
\hline \multicolumn{11}{|l|}{ Colon } \\
\hline$P Y Y$ & $\begin{array}{c}M \\
F\end{array}$ & $\begin{array}{l}33 \cdot 3 \\
53 \cdot 2\end{array}$ & $\begin{array}{r}8.5 \\
11.5\end{array}$ & $\begin{array}{l}12 \cdot 7 \\
18 \cdot 6\end{array}$ & $\begin{array}{l}3 \cdot 8 \\
5 \cdot 1\end{array}$ & $\begin{array}{l}11.5 \\
41.7\end{array}$ & $\begin{array}{r}4.3 \\
21 \cdot 6\end{array}$ & 0.040 & 0.039 & 0.52 \\
\hline
\end{tabular}

GIP, glucose-dependent insulinotropic polypeptide; $S G L T 1$, sodium glucose co-transporter 1; $P Y Y$, peptide tyrosine tyrosine.

${ }^{a, b}$ Mean values with unlike superscript letters were significantly different between the diets $(P \leq 0.01)$.

${ }^{\mathrm{x}, \mathrm{y}}$ There was a significant diet $\times$ sex interaction $(P \leq 0 \cdot 01)$. 
Table 5. Hepatic gene expression in the offspring of dams fed a control, high-protein or high-prebiotic fibre diet during pregnancy and lactation

(Mean values with their standard errors, $n 8-10$ per group)

\begin{tabular}{|c|c|c|c|c|c|c|c|c|c|c|}
\hline & \multirow[b]{3}{*}{ Sex } & \multicolumn{6}{|c|}{ Maternal diet } & & & \\
\hline & & \multicolumn{2}{|c|}{ Control } & \multicolumn{2}{|c|}{ High protein } & \multicolumn{2}{|c|}{ High fibre } & \multicolumn{3}{|c|}{$P$ (two-way ANOVA) } \\
\hline & & Mean & SE & Mean & SE & Mean & SE & Diet & Sex & Diet $\times$ sex \\
\hline \multirow[t]{2}{*}{ FAS } & M & $1.4^{\mathrm{b}}$ & 0.3 & $0.86^{a}$ & 0.24 & $1 \cdot 8^{\mathrm{b}}$ & 0.5 & 0.006 & 0.18 & 0.31 \\
\hline & $\mathrm{F}$ & $1.7^{b}$ & 0.4 & $0.75^{\mathrm{a}}$ & 0.11 & $3 \cdot 1^{b}$ & 1.0 & & & \\
\hline \multirow[t]{2}{*}{ PEPCK } & $\mathrm{M}$ & $4 \cdot 3$ & 0.8 & 3.9 & 0.7 & 7.5 & $1 \cdot 2$ & 0.11 & 0.006 & 0.037 \\
\hline & $\mathrm{F}$ & $2 \cdot 8$ & 0.8 & 3.9 & 0.7 & 3.0 & 0.7 & & & \\
\hline \multirow[t]{2}{*}{$P G C 1 \alpha$} & M & $2 \cdot 6^{x}$ & 0.9 & $1 \cdot 8^{\mathrm{x}}$ & 0.4 & $2 \cdot 7^{x}$ & 0.7 & 0.004 & 0.001 & 0.006 \\
\hline & $\mathrm{F}$ & $8 \cdot 1^{y}$ & 0.9 & $4 \cdot 7^{x, y}$ & 1.2 & $2 \cdot 9^{x}$ & 0.9 & & & \\
\hline
\end{tabular}

FAS, fatty acid synthase; PEPCK, phosphoenolpyruvate carboxykinase; PGC1 $\alpha$, PPAR $\gamma$ co-activator 1- $\alpha$.

$\mathrm{a}, \mathrm{b}$ Mean values with unlike superscript letters were significantly different between the diets $(P \leq 0.01)$.

$x, y$ There was a significant diet $x$ sex interaction $(P \leq 0.01)$.

muscle metabolism shown by Rehfeldt et $a l^{(32)}$ in animals suckled by HP dams. The differences in body weight in females could be partially due to the decreased availability of NEFA, which may be involved in the regulation of hepatic fatty acid metabolism, although despite similar decreases in NEFA in males, they did not have a lower body weight ${ }^{(39)}$. The decreased expression of FAS in our HP1 animals may be affected by the increased availability of NEFA, affecting hepatic fatty acid metabolism. A similar decrease in FAS mRNA was observed in our previous work in rats aged 28 and $35 \mathrm{~d}^{(22)}$. This may be a lasting effect from the maternal diet, as diets low in carbohydrates and high in protein have been shown to decrease hepatic FAS mRNA ${ }^{(40-43)}$. Male HP1 animals showed decreased $P G C 1 \alpha$ expression, which is characteristic for the animals consuming a high-fat diet and/or with hypertriacylglycerolaemia ${ }^{(44)}$. This decreased expression, along with decreased PEPCK expression, could be related to their improved HOMA-IR score

Decreases in the expression of GLUT2 and SGLT1 in the ileum of HF1 and HP1, and HF1 males, respectively, could be linked, particularly in HP1, to improvements in glucose homeostasis as demonstrated by improved HOMA-IR scores. However, SGLT1 mRNA expression, in particular, is not always related to SGLT1 activity, as protein levels are more influential than mRNA levels ${ }^{(45)}$. Decreases in the expression of these transporters in HF1 may be related to differences in the gut microbiota, which remains to be examined. Should there be an alteration in the microbial community leading to increased fermentation, and therefore increased SCFA production, the decreased carbohydrate content in the lumen would result in the decreased expression of SGLT1. Glucose transport has been shown to decrease in the distal portions of the small intestine, and the decrease is more dramatic as rats age ${ }^{(46)}$. This could contribute to the differences seen in SGLT1 expression in the ileum.

We have previously demonstrated that increases in GLP-1 and PYY secretion along with the up-regulation of $P Y Y$ and proglucagon expression occur in response to prebiotic consumption in rats ${ }^{(22,24)}$. In this model, only the dams consumed the prebiotic fibre, and therefore we might expect that the effect may not be passed on to the offspring. This is largely confirmed, although the HF1 offspring did have a higher PYY AUC than HP1 offspring but not C1. We acknowledge that the use of anaesthesia during the OGTT could potentially influence the concentrations of satiety hormones in the plasma, although Zardooz et al. ${ }^{(47)}$ showed that isoflurane had no effect on glucose and insulin levels in fed rats and decreased insulin but not glucose in fasted rats. Similarly, Andrikopoulos et al. ${ }^{(48)}$ showed that there was no difference in blood glucose concentrations, and the ability to differentiate glucose tolerance in a chow-fed $v$. high-fat diet-fed mice under anaesthesia or while conscious was the same. While the plasma concentrations of satiety hormones obtained in our anaesthetised rats are within expected ranges, we have recently made procedural advancements that allow us to obtain sufficient blood from the tip of the tail in conscious rats and thereby avoid the use of anaesthesia.

While there were no differences in male body weight or composition, males did exhibit changes in hepatic and intestinal gene expression, as well as differences in satiety hormones and hepatic lipid storage and glucose control as measured by liver TAG, plasma NEFA and HOMA-IR. It is possible that prolonged exposure to the HFS diet could eventually result in differences in adiposity in response to the observed changes related to hepatic lipid storage and metabolism, especially since significant differences in female body weight were not apparent until 22 weeks. Sex differences observed here, wherein females were more affected than males, could be due to the differences in placental gene expression. It has been shown that placentae of females have been found to have twice as many changes in gene expression compared with the placentae of males, making females more sensitive to environmental changes such as diet ${ }^{(49)}$.

In conclusion, we demonstrated that in utero exposure to a diet high in protein or prebiotic fibre has a lasting effect on offspring adiposity, hepatic lipid storage and expression of genes related to glucose and lipid metabolism. Within the time frame that we examined, the effect was more pronounced in female than in male offspring. Taken together, these findings suggest that a maternal diet high in protein 
appears to have some adverse effects, particularly with regard to body composition, while a high-prebiotic maternal diet appears to provide some protection against an obese phenotype in offspring once they reach adulthood.

\section{Acknowledgements}

The present study was supported by a research grant from the Natural Sciences and Engineering Research Council (RGPIN 238382-2008, 2009). M. C. H. was supported by an NSERC Postgraduate Scholarship, a Frederick Banting and Charles Best Canada Graduate Scholarship, and a CIHR Training Award in Genetics, Child Development and Health.

M. C. H. declares no conflict of interest. R. A. R. previously held a research grant from Beneo-Orafti, Inc., the manufacturer of Raftilose P95 and Raftiline HP, for a project unrelated to the present study.

\section{References}

1. World Health Organization (2006) Obesity and Overweight. http://www.who.int/mediacentre/factsheets/fs311/en/index. html

2. Lucas A (1998) Programming by early nutrition: an experimental approach. $J$ Nutr 128, 410S-406S.

3. Taylor PD \& Poston L (2007) Developmental programming of obesity in mammals. Exp Physiol 92, 287-298.

4. Maurer AD, Chen Q, McPherson C, et al. (2009) Changes in satiety hormones and expression of genes involved in glucose and lipid metabolism in rats weaned onto diets high in fiber or protein reflect susceptibility to increased fat mass in adulthood. J Physiol Lond 587, 679-691.

5. Daimiel L, Vargas T \& Ramirez de Molina A (2012) Nutritional genomics for the characterization of the effect of bioactive molecules in lipid metabolism and related pathways. Electrophoresis 33, 2266-2289.

6. Theuwissen E \& Mensink RP (2008) Water-soluble dietary fibers and cardiovascular disease. Physiol Behav $\mathbf{9 4}$ 285-292.

7. Vuksan V, Rogovik AL, Jovanovski E, et al. (2009) Fiber facts: benefits and recommendations for individuals with type 2 diabetes. Curr Diabetes Reports 9, 405-411.

8. Qui C, Coughlin KB, Frederick IO, et al. (2008) Dietary fiber intake in early pregnancy and risk of subsequent preeclampsia. Am J Hypertens 21, 903-909.

9. Liu S (2002) Intake of refined carbohydrates and whole grain foods in relation to risk of type 2 diabetes mellitus and coronary heart disease. J Am Coll Nutr 21, 298-306.

10. Parnell JA \& Reimer RA (2009) Weight loss during oligofructose supplementation is associated with decreased ghrelin and increased peptide $\mathrm{YY}$ in overweight and obese adults. Am J Clin Nutr 89, 1751-1759.

11. Maurer AD \& Reimer RA (2011) Maternal consumption of high prebiotic fiber or protein diets during pregnancy and lactation differentially influences satiety hormones and expression of genes involved in glucose and lipid metabolism in offspring in rats. Br J Nutr 105, 329-338.

12. Pyra KA, Saha DC \& Reimer RA (2012) Prebiotic fiber increases hepatic acetyl CoA carboxylase phosphorylation and suppresses glucose-dependent insulinotropic polypeptide secretion more effectively when used with metformin in obese rats. J Nutr 142, 213-220.
13. Parnell JA \& Reimer RA (2012) Prebiotic fibres dose-dependently increase satiety hormones and alter Bacteroidetes and Firmicutes in lean and obese JCR:LA cp rats. Br J Nutr 107, 601-613.

14. Rifas-Shiman SL, Rich-Edwards JW, Kleinman KP, et al. (2009) Dietary quality during pregnancy varies by maternal characteristics in Project Viva: a US cohort. J Am Diet Assoc 109, 1004-1011.

15. Bang SW \& Lee SS (2009) The factors affecting pregnancy outcomes in the second trimester pregnant women. Nutr Res Pract 3, 134-140.

16. Andreasyan K, Posonby AL, Dwyer T, et al. (2007) Higher maternal dietary protein intake in late pregnancy is associated with a lower infant ponderal index at birth. Eur J Clin Nutr 61, 498-508.

17. Rush D, Stein Z \& Susser M (1980) A randomized controlled trial of prenatal nutritional supplementation in New York City. Pediatrics 65, 683-697.

18. Campbell DM, Hall MH, Barker DJ, et al. (1996) Diet in pregnancy and the offspring's blood pressure 40 years later. $\mathrm{BrJ}$ Obstet Gynaecol 103, 273-280.

19. Shiell AW, Campbell-Brown M, Haselden S, et al. (2001) High-meat, low-carbohydrate diet in pregnancy: relation to adult blood pressure in the offspring. Hypertension $\mathbf{3 8}$, 1282-1288.

20. Herrick K, Phillips DI, Haselden S, et al. (2003) Maternal consumption of a high-meat, low-carbohydrate diet in late pregnancy: relation to adult cortisol concentrations in the offspring. J Clin Endocrinol Metab 88, 3554-3560.

21. Daenzer M, Ortmann S, Klaus S, et al. (2002) Prenatal high protein exposure decreases energy expenditure and increases adiposity in young rats. J Nutr 132, 142-144.

22. Maurer AD, Eller LK, Hallam MC, et al. (2010) Consumption of diets high in prebiotic fiber or protein during growth influences the response to a high fat and sucrose diet in adulthood in rats. Nutr Metab 7, 77.

23. Reeves PG, Nielsen FH \& Fahey GC Jr (1993) AIN-93 purified diets for laboratory rodents: final report of the American Institute of Nutrition ad hoc writing committee on the reformulation of the AIN-76A rodent diet. J Nutr 123, 1939-1951.

24. Reimer RA \& Russell JC (2008) Glucose tolerance, lipids and GLP-1 secretion in JCR:LA-cp rats fed a high protein fiber diet. Obesity 16, 40-46.

25. Silver N, Best S, Jiang J, et al. (2006) Selection of housekeeping genes for gene expression studies in human reticulocytes using real-time PCR. BMC Mol Biol 7, 33.

26. Godfrey KM, Lillycrop KA, Burdge GC, et al. (2007) Epigenetic mechanisms and the mismatch concept of the developmental origins of health and disease. Pediatr Res 61, $5 \mathrm{R}-10 \mathrm{R}$.

27. Berends LM, Fernandez-Twinn DS, Martin-Gronert MS, et al. (2012) Catch-up growth following intra-uterine growthrestriction programmes an insulin-resistant phenotype in adipose tissue. Int J Obes (Lond) (Epublication ahead of print version 11 December 2012).

28. Kucia M, Langhammer M, Gors S, et al. (2011) High-protein diet during gestation and lactation affects mammary gland mRNA abundance, milk composition and pre-weaning litter growth in mice. Animal 5, 268-277.

29. Turnbaugh PJ, Ley RE, Mahowald MA, et al. (2006) An obesity-associated gut microbiome with increased capacity for energy harvest. Nature 444, 1027-1031.

30. Guilloteau P, Zabielski R, Hammon HM, et al. (2009) Adverse effects of nutritional programming during prenatal and early postnatal life, some aspects of regulation and potential 
prevention and treatments. J Physiol Pharmacol 60, Suppl. 3 , $17-35$.

31. Delamaire E, Parnet P, Coupe B, et al. (2012) Long term metabolic impact of high protein neonatal feeding: a preliminary study in male rat pups born with a low birth weight. Clin Nutr 31, 741-748.

32. Rehfeldt C, Langhammer M, Kucia M, et al. (2012) Enhanced sensitivity of skeletal muscle. growth in offspring of mice long-term selected for high body mass in response to a maternal high-protein/low-carbohydrate diet during lactation. Eur J Nutr (Epublication ahead of print version 8 August 2012).

33. Langhammer M, Derno M, Dietrich N, et al. (2006) Fetal programming of offspring growth due to maternal high protein diet is genotype dependent in mice. J Anim Sci 84, Suppl. 1, 144.

34. Ong KK, Ahmed ML, Sherriff A, et al. (1999) Cord blood leptin is associated with size at birth and predicts infancy weight gain in humans. ALSPAC Study Team. Avon Longitudinal Study of Pregnancy and Childhood. J Clin Endocrinol Metab 84, 1145-1148.

35. Gohlke BC, Huber A, Hecher K, et al. (2005) Fetal insulinlike growth factor (IGF)-I, IGF-II, and ghrelin in association with birth weight and postnatal growth in monozygotic twins with discordant growth. J Clin Endocrinol Metab 90, $2270-2274$

36. Jennings BJ, Ozanne SE, Dorling MW, et al. (1999) Early growth determines longevity in male rats and may be related to telomere shortening in the kidney. FEBS Lett 448, 4-8.

37. Rozan P, Nejdi A, Hidalgo S, et al. (2008) Effects of lifelong intervention with an oligofructose-enriched inulin in rats on general health and lifespan. Br J Nutr 100, 1192-1199.

38. Delzenne NM \& Kok NN (1999) Biochemical basis of oligofructose-induced hypolipidemia in animal models. $J$ Nutr 129, 1467S-1470S.

39. Daubioul C, Rousseau N, Demeure R, et al. (2002) Dietary fructans, but not cellulose, decrease triglyceride accumulation in the liver of obese Zucker fa/fa rats. I Nutr 132, 967-973.

40. Morris KL, Namey TC \& Zemel MB (2003) Effects of dietary carbohydrate on the development of obesity in heterozygous Zucker rats. J Nutr Biochem 14, 32-39.

41. Pichon L, Huneau J-F, Fromentin G, et al. (2006) A highprotein, high-fat, carbohydrate-free diet reduces energy intake, hepatic lipogenesis, and adiposity in rats. $J$ Nutr 136, 1256-1260.

42. Zhang XH, Hua JZ, Wang SR, et al. (2007) Post-weaning isocaloric hyper-soybean oil versus a hyper-carbohydrate diet reduces obesity in adult rats induced by a high-fat diet. Asia Pac J Clin Nutr 16, Suppl., 368-373.

43. Stepien M, Gaudichon C, Fromentin G, et al. (2011) Increasing protein at the expense of carbohydrate in the diet downregulates glucose utilization as glucose sparing effect in rats. PLoS One 6, e14664.

44. Barroso E, Rodriquez-Calvo R, Serrano-Marco L, et al. (2011) The PPAR $\beta / \delta$ activator GW501516 prevents the down-regulation of AMPK caused by a high-fat diet in liver and amplifies the PGC-1 $\alpha$-Lipin 1-PPAR $\alpha$ pathway leading to increased fatty acid oxidation. Endocrinology 152, 1848-1859.

45. Ferraris RP (2001) Dietary and developmental regulation of intestinal sugar transport. Biochem J 360, 265-276.

46. Doubek WG \& Armbrecht HJ (1987) Changes in intestinal glucose transport over the lifespan of the rat. Mech Ageing Dev 39, 91-102.

47. Zardooz H, Rostamkhani F, Zaringhalam J, et al. (2010) Plasma corticosterone, insulin and glucose changes induced by brief exposure to isoflurane, diethyl ether and $\mathrm{CO}_{2}$ in male rats. Physiol Res 59, 973-978.

48. Andrikopoulos S, Blair AR, Deluca N, et al. (2008) Evaluating the glucose tolerance test in mice. Am J Physiol Endocrinol Metab 295, E1323-E1332.

49. Rosenfeld CS (2012) Effects of maternal diet exposure to bisphenol A on sexually dimorphic responses in conceptuses and offspring. Reprod Domest Anim 47, Suppl. 4, $23-30$. 